\title{
Kidney pseudotumour diagnosed by emission computed tomography
}

\author{
E D WILLIAMS, C PARKER
}

\begin{abstract}
Emission computed tomography is a new, useful imaging technique; when a rotating gamma camera capable of such imaging is used multiple adjacent transverse sections may be obtained simultaneously, from which coronal and sagittal sections may be computed. The technique was used in a man undergoing urological investigation in whom excretion urography indicated a space-occupying lesion in the left kidney. Ultrasonography and radionuclide imaging showed nothing abnormal, but emission computed tomography using a rotating gamma camera showed that functioning cortical tissue extended across the middle of the left kidney. Radiographs were therefore reviewed and ultrasonography repeated, and it was concluded that the abnormality was a hypertrophied column of Bertin.

Emission tomographic imaging of the kidney is a useful adjunct to other non-invasive studies.
\end{abstract}

\section{Introduction}

The clinical usefulness of emission computed tomography as a new radionuclide imaging technique for detecting lesions in the brain and liver has been described by Ell et $a l^{1}$ and Khan et al. ${ }^{2}$ These workers used a specially designed scanner. Rotating gamma cameras capable of emission tomographic imaging are now being installed in many hospitals, and this alternative approach to emission tomography has several advantages. The technique using a rotating gamma camera permits multiple adjacent transverse sections to be obtained simultaneously, and these can be used subsequently to compute coronal and sagittal sections. $^{3}$ These additional section views can aid recognition of

Regional Medical Physics Department, Sunderland District Genera Hospital, and Urology Department, Royal Infirmary, Sunderland, Tyne and Wear

E D WILLIAMS, PHD, principal physicist

C PARKER, FRCs, consultant urologist abnormalities. We are currently investigating the use of this technique in kidney imaging and present here a striking example of its usefulness.

\section{Case report}

An excretion urogram obtained in a 44-year-old man undergoing urological investigations showed a central mass effect in the left kidney (fig 1), suggesting that a space-occupying lesion was present. $\mathrm{He}$ was therefore referred for ultrasonography and radionuclide imaging. Ultrasonography of the kidneys was performed using a $3.5 \mathrm{MHz}$ linear array real-time scanner (Toshiba SAL20) and a grey-scale B-scanner with a 3.5 MHz focused transducer (Diasonograph 4200 , Fischer Ultrasound). No definite abnormality was shown in either kidney.

Radionuclide imaging was subsequently performed three hours after intravenous administration of $74 \mathrm{MBq}(2 \mathrm{mCi})$ technetium- $99 \mathrm{~m}-$ labelled dimercaptosuccinic acid, and static images (500 000 counts each) were obtained in posterior and right and left posterior oblique views using a large-field gamma camera (General Electric 400T). These images appeared completely normal (fig $2 a, b, c)$. Without any

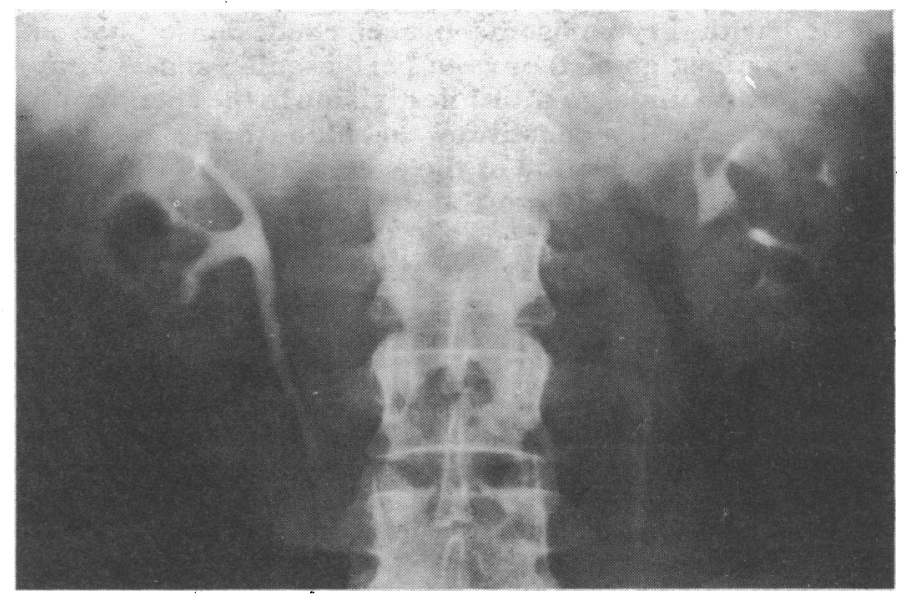

FIG 1-Excretion urogram (25-minute film) showing central mass effect in left kidney. 


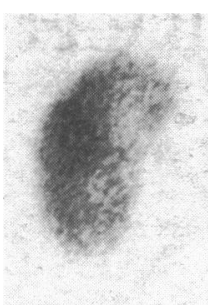

(a)

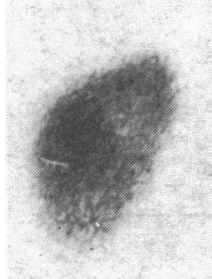

(c)

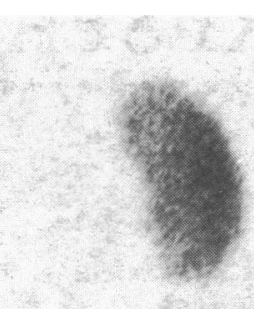

(b)

\section{b)}

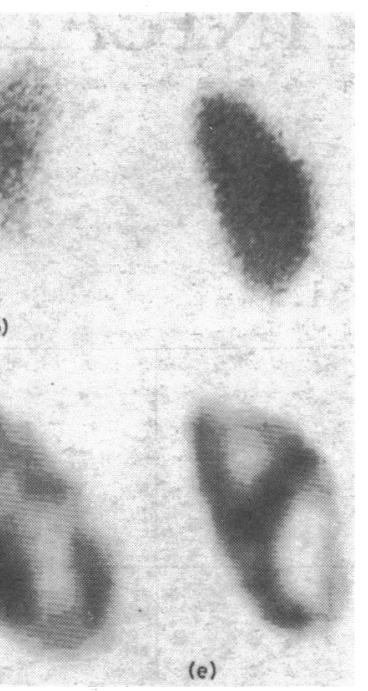

(e)

FIG 2-Conventional gamma-camera images: (a) posterior, $(b)$ right posterio oblique, and (c) left posterior oblique; and sagittal sections through $(d)$ right and $(e)$ left kidney, which clearly show hypertrophied column of Bertin.

further radioactive substance being given, emission computed tomography of the kidneys was then performed using the same gamma camera connected to an image analysis computer (Gamma-11, Digital Equipment $\mathrm{Co}$ ) in its rotation mode. Data were collected for $20 \mathrm{~s}$ at each of 64 views equally spaced through $360^{\circ}$ around the patient. Sagittal sections were then computed (fig $2 d, e$ ), which clearly showed that in the left kidney the functioning cortical tissue extended across the middle of the kidney. The radiographs were then reviewed and another ultrasound investigation done, after which it was concluded that the left kidney showed partial reduplication of the collecting system with interposed solid tissue having the characteristics of normal renal parenchyma. The renal abnormality was therefore a hypertrophied column of Bertin.

\section{Discussion}

The column of Bertin may be a source of considerable confusion in radiographic investigation of the kidney since it may simulate a renal tumour on an excretion urogram and may require angiography for diagnosis. ${ }^{4}$ Ultrasonography may be unhelpful, not only if the patient yields poor-quality images owing to, for example, obesity but also because the calyceal appearance in healthy kidneys varies considerably and a small amount of distortion is therefore easily missed. Conventional radionuclide images may also, as in this case, be unhelpful. The usual procedure to determine the nature of the suspected lesion would then be to proceed to selective renal angiography. ${ }^{4}$ In this case the necessity for this invasive investigation of a healthy kidney was obviated by the clear tomographic radionuclide images obtained. In other patients we have found that emission tomographic imaging of the kidney can be a useful adjunct to other non-invasive studies. ${ }^{5}$

We are grateful to Dr P G Rose, consultant radiologist, for his advice and opinion on this case.

\section{References}

1 Ell PJ, Deacon JM, Ducasson D, Brendel A. Emission and transmission brain tomography. Br Med 7 1980;280:438-40.

2 Khan O, Ell PJ, Jarrit PH, Cullum ID, Williams ES. Comparison between emission and transmission computed tomography of the liver. Br Med F 1981 ;283:1212-4.

3 Larsson SA. Gamma camera emission tomography. Acta Radiol [Suppl] $1980 ; 363: 1-75$.

4 Witten DM, Myers GH, Utz DC, eds. Tumours of the genitourinary tract. Emmett's clinical urography. 4th ed. Philadelphia: W B Saunders, 1977 1493.

5 Williams ED, Parker C, Roy RR, Rankin D, Holland A, Brown M Multiple section emission computed tomography of the kidney: an assessment. In: Joekes AM, Constable AR, Brown NJG, Tauxe WN, eds. Radionuclides in nephrology. London: Academic Press, 1982:71-5.

\title{
Cryptic stage of sleeping-sickness trypanosome developing in choroid plexus epithelial cells
}

\author{
M O ABOLARIN, D A EVANS, D G TOVEY, W E ORMEROD
}

\begin{abstract}
Electronmicrographs of the choroid plexus from rats infected with Trypanosoma brucei rhodesiense showed that trypomastigotes from the perivascular spaces may penetrate and undergo multiple division in the ependymal cells which locally constitute the blood-brain barrier. Progressive degeneration of the ependymal cell liberates trypomastigotes back into the perivascular space, from which re-entry into the blood may occur. Re-entry to the blood does not take place from any tissues other than the brain and its membranes.
\end{abstract}

\footnotetext{
London School of Hygiene and Tropical Medicine, London WC1E 7HT

M O ABOLARIN, PHD, principal lecturer, Kwara State College, Nigeria D A EVANS, PHD, senior lecturer

D G TOVEY, DIPEM, senior medical laboratory scientific officer

W E ORMEROD, DM, DSC, senior lecturer
}

These findings suggest that the ependymal cells of the choroid plexus are the site of the cryptic stage of the sleeping-sickness trypanosome.

\section{Introduction}

African sleeping sickness is regarded as one of the most enigmatic of diseases because of its tendency to relapse after apparently successful treatment with chemotherapy. Similarly, when spontaneous remission occurs parasitaemia may be re-established months or even years after the initial infection. This occurs particularly with the Gambian form. Such behaviour suggests the existence of a cryptic stage somewhere in the tissues from which relapses may be generated. Such a cryptic stage occurs in Plasmodium vivax malaria. Hitherto, however, only indirect evidence of a cryptic stage has been documented, and one study suggested the choroid plexus as a site where cryptic forms of the sleeping-sickness parasite might be expected to develop. ${ }^{1}$

Recent work on the relapse of Trypanosoma brucei infections 